\title{
Tuberous Sclerosis Complex Syndrome Cardiovascular and Renal Manifestation of Tuberous Sclerosis Complex and Summary of the Revised Diagnostic Criteria
}

\author{
Dr. Jainesh Dodia ${ }^{1}$, Dr. (Brig) K. Sahoo ${ }^{2}$
}

\begin{abstract}
Tuberous sclerosis complex Syndrome (TSCs) is a dominantly inherited disorderaffecting multiple organs; caused by mutations of either the TSC1 or TSC2 gene encodinghamartin andtuberinrespectively. It is characterized by the development of benign tumorsaffecting different body systems.It is important tomake an earlydiagnosis of TSC so that lifelong monitoring, earlyrecognition of complicationsand proactivetreatment can lower the morbidity and mortalityrates. We report a case of 3 Month old male infant in India with the features of Tuberous sclerosis complex syndrome like hypopigmented macules (>3), Rabdomyoma of heart,angiolipoma of the kidney, seizures since birth on background of family history of elder sister having (adenoma sebaceum, interact able seizures and mentally challenges since birth) also mother having similar adenoma sebaceum and seizures but due to family background of low economic status has not undergone further workup or evaluation. The central nervous system findings in this young baby were the first to be described, clinical findings of progressively increasing seizure episodes since day 6 of life and there are multiple hypopigmented macules over thigh, back and near axillary region.
\end{abstract}

Keywords:

\section{Introduction}

Von Recklinghausen first described tuberous sclerosis in 1862. Desire-Magloire Bourneville (a French physician)coined the term sclerose tubereuse, from which the name of the disease has evolved. Sherlock coined the term EPILOIA encompassing the clinical triad of tuberoussclerosis (Epi: epilepsy, Loi: low intelligence, A: adenoma sebaceum).

As the manifestations of thedisease are variegated in nature, the term Tuberous Sclerosis Complex (TSC) is now widely used. It is an autosomal dominantneurocutaneous syndrome, characterized by the development of benign tumors such as neurofibromas and angiofibromas locatedanywhere in the body (skin, central nervous system, heart,kidneys etc).
Patientswith TSC present mutations of the TSC1and TSC2 genes, which intervene in cell cycle regulation. This is a dominantautosomal hereditary disease, though $60-70 \%$ of all cases are the result of spontaneous mutations.

Tuberous Sclerosis Complex manifests with variable signs and symptoms together with angiofibromas distributed in a characteristic "butterfly" pattern on the face and forehead. The most important neurological problems aremental retardation, seizures, autism and learning difficulties.

Cardiac rhabdomyomas are hamartomatous growths or benign tumors composed ofcardiac myocytes, and they represent the classic neonatalmanifestation of cardiac disease in TSC.

Diagnostic Criteria to diagnose TSC.

Clinical diagnostic criteria

Major features

1. Hypomelanotic macules ( $\geq 3$, at least 5-mm diameter)

2. Angiofibromas $(\geq 3)$ or fibrous cephalic plaque

3. Ungual fibromas $(\geq 2)$

4. Shagreen patch

5. Multiple retinal hamartomas

6. Cortical dysplasias*

7. Subependymal nodules

8. Subependymal giant cell astrocytoma

9. Cardiac rhabdomyoma

10. Lymphangioleiomyomatosis (LAM)

11. Angiomyolipomas $(\geq 2)$

\section{Minor features}

1. "Confetti" skin lesions

2. Dental enamel pits ( $>3)$

3. Intraoral fibromas $(\geq 2)$

4. Retinal achromicpatch

5. Multiple renal cysts

6. Nonrenalhamartomas 


\section{International Journal of Science and Research (IJSR) \\ ISSN (Online): 2319-7064 \\ Index Copernicus Value (2013): 6.14 | Impact Factor (2015): 6.391}

\section{Case Report Findings}

We herein report a case of 3 month old male infant who presented with seizures since $6^{\text {th }}$ day of birth, hypopigmented macules ( $>3$ ), Rabdomyoma of heart and angiolipoma of the kidneywhich onfurther evaluation by MRI Brain showed $>3$ major features of subependymal nodules, cortical tubers and radiating white matter hyperintensity on T1WI.

\section{Discussion}

Tuberous sclerosis is a rare syndrome with an estimated incidence varying from 1 in 20,000 to 1 in 150,000 and the incidence has been reported to be as high as 1 in 10,000 .
Patients with Tuberous sclerosis complex (TSC) range from intellectually normal to severely mentally retarded. TSC is often associated with mental retardation (in $70 \%$ of cases) and epilepsy (90\%). Seizures are the most commonneurologic symptom of TSC occurring in92\% of patients.

Thickened cortex with focal areas of predominantly FLAIR hyperintensity and T1WI isointensity and T2WI hyperintensity are noted in both frontal, parietal and occipital lobes with gyral swelling. Tiny subependymal nodules are seen in both lateral ventricle which appears isointense on T1WI and Hypointense on T2WI.
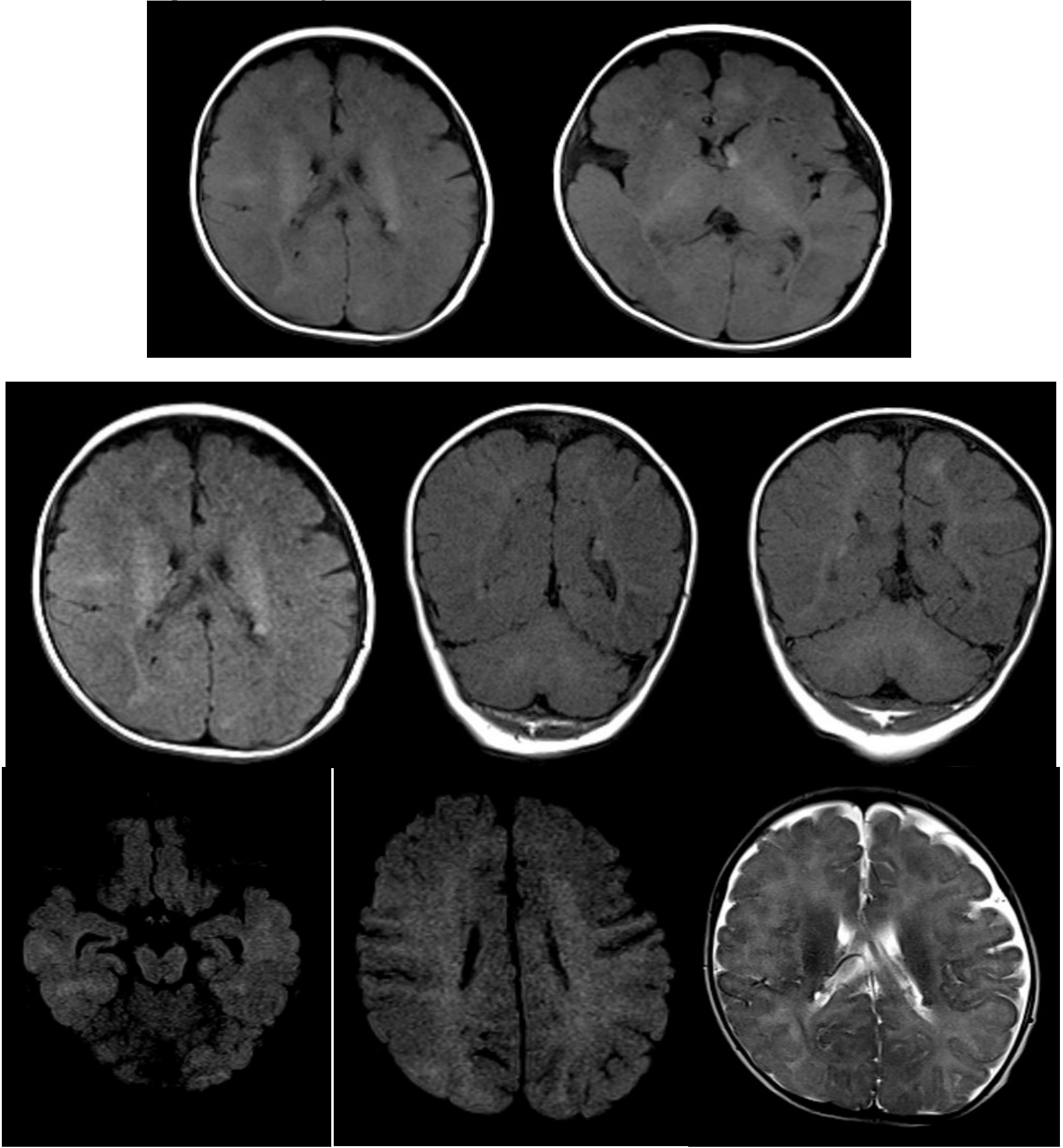

Volume 5 Issue 4, April 2016 


\section{International Journal of Science and Research (IJSR) \\ ISSN (Online): 2319-7064}

Index Copernicus Value (2013): 6.14 | Impact Factor (2015): 6.391

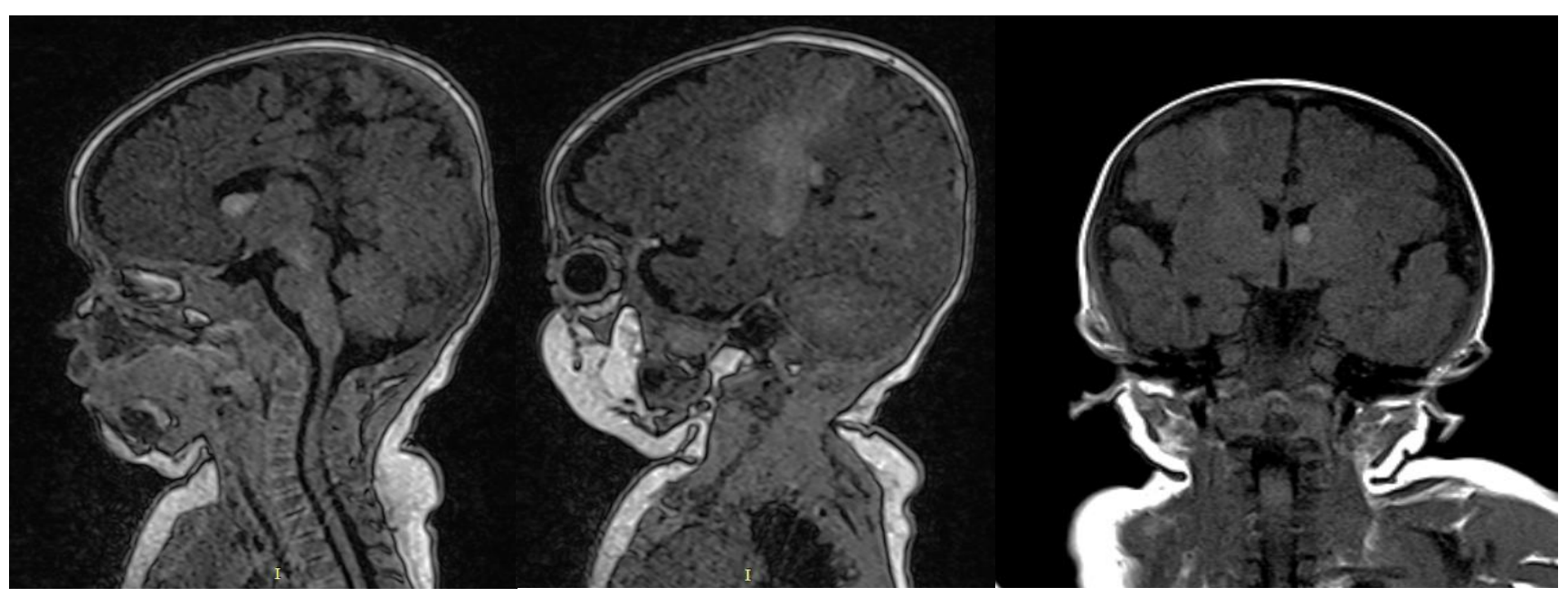

Neurologic symptoms and complications due to the development of cortical tubers, subependymal nodules and subependymalgiant cell astrocytomas (SEGA) are common in patients with TSC as we found subependymal nodules and cortical tubers on MRI brain scan.

Most important hamartomas are cerebral cortical tubers, which are regions of abnormal cortical architecture with distinctive large neuronal cells. Cortical tubers cause some of the most important clinical manifestations of tuberous sclerosis complex syndrome.

Tuberous sclerosis complex ischaracterized by neurocutaneous manifestations and a careful skin examination of patients suspected to have TSC is mandatory.

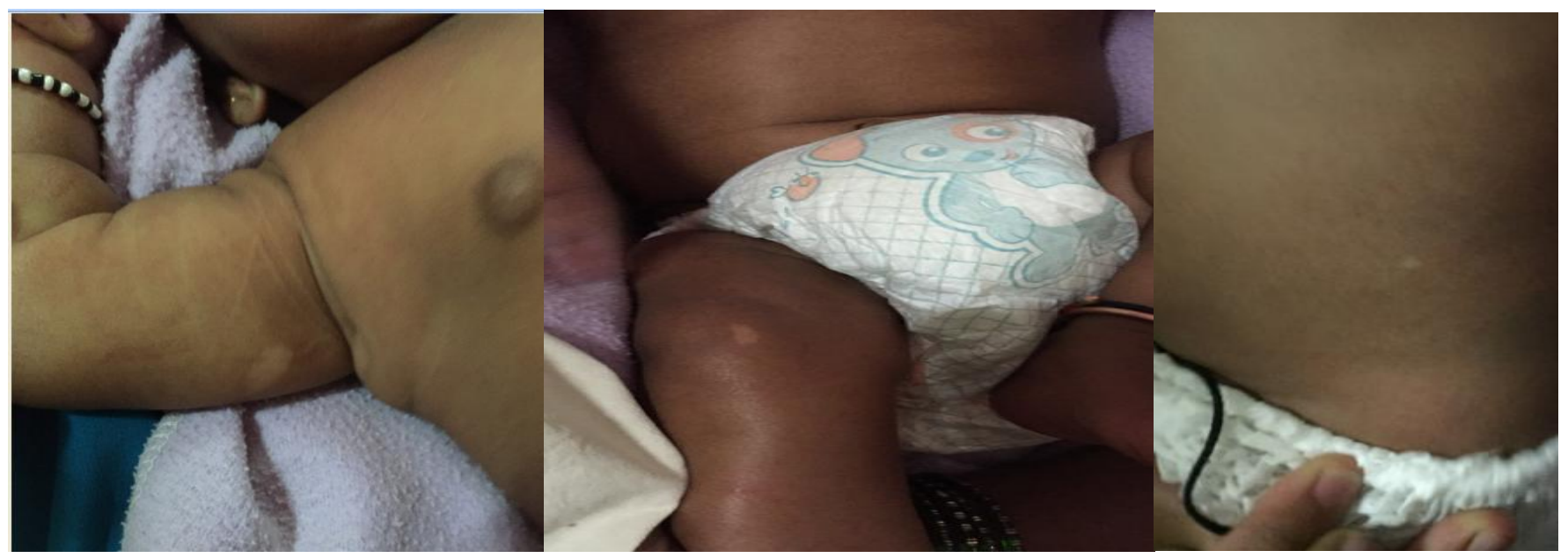

(As revealed in the study of Jozwiak et al, the frequencies of patients with hypopigmented macules, facial angiofibromas, forehead or scalp plaque, shagreen patch and periungual fibroma were $97 \%$, 75\%, 48\%, 19\% and15\% respectively.)

Two types of renal lesions occur inpatients with tuber sclerosis:angiomyolipomas and renal cysts. Theymay be found independently or together they may be unilateral, bilateral, single or multiple. Angiomyolipomas are benign immature and asymptomatic but spontaneous rupture and subsequent hemorrhage in toretroperitoneum may occur and are the cause of chronic renal failure that may prove fatal.

Our case reported with angiomyolipomas of the Left Kidney.

In the heart, the most frequent and characteristic type of tumor is cardiacrhabdomyomas. Incidence of cardiacrhabdomyomas in children with tuberoussclerosis is higher than in adult patients with tuberous sclerosis.
It has been suggested that such lesions tend to regressin early infancy and adolescence and arenormally observed before age 25 years in $30-50 \%$ of all cases, and are also a causeof early death. Our case reported had rabdomyoma in wall of right ventricular.

USG: screening of abdomen showed a echogenic lesion in lower pole of left kidney showing contour bulge likely to be angiomyolipoma.

Up to $80 \%$ of adult patients with TSC will developangiomyolipoma.

Our case reported with epilepsy since birth (6 $6^{\text {th }}$ day of life), hypomelanotic macules and (USG screening showed round to oval echogenic lesion in right ventricular myocardium suspicious of rabdomyoma and echogenic lesion in lower pole of left kidney suspicious of angiolipoma.) 


\section{International Journal of Science and Research (IJSR) \\ ISSN (Online): 2319-7064}

Index Copernicus Value (2013): 6.14 | Impact Factor (2015): 6.391

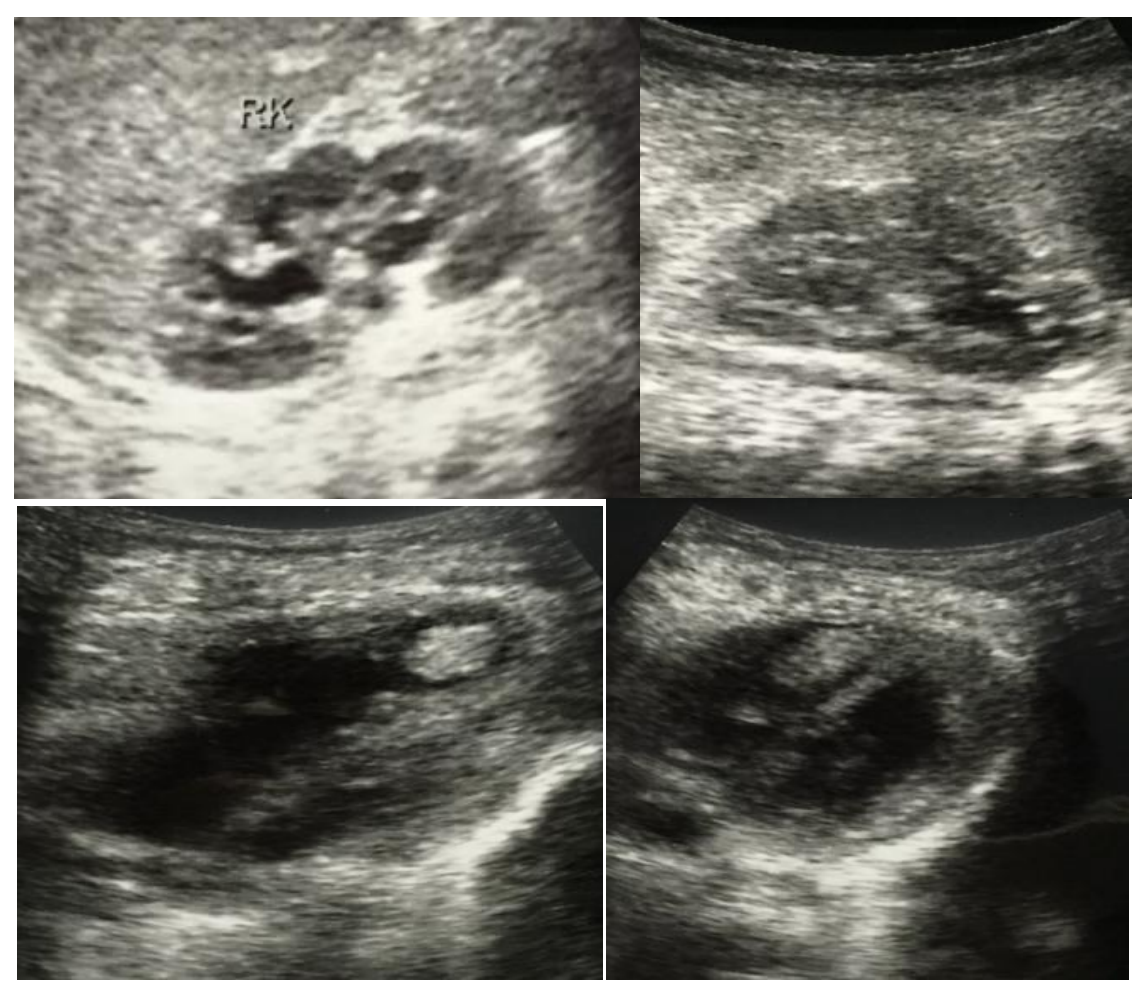

\section{Conclusion}

This case report is a good example of complex nature of tuberous sclerosis. Our case report showed infantile spasms and hypo arrhythmiaare more severely affected than those with any other form of epilepsy. The aim of this report is to present various clinical and radiological features of a young male infant with tuberous sclerosis who exhibited multiple hamartomas of various organ system. Tuberous sclerosis is a rare neurocuteneous syndrome exhibiting multiple hamartomatous proliferations that may involve multiple organ system such as brain, kidney, heart, lungs, eyes and skin.

Surveillance and Management Recommendations for Newly Diagnosed or Suspected TSC Summary Table

\begin{tabular}{|c|c|}
\hline $\begin{array}{l}\text { Organ System or } \\
\text { Specialty Area }\end{array}$ & Recommendation \\
\hline Genetics & $\begin{array}{l}\text { Obtain 3-generation family history to assess for additional family members at risk of TSC } \\
\text { - Offer genetic testing for family counseling or when TSC diagnosis is in question but cannot be clinically } \\
\text { confirmed }\end{array}$ \\
\hline Brain & $\begin{array}{l}\text { - Perform MRI of the brain to assess for the presence of tubers, subependymal nodules (SEN), migrational } \\
\text { defects, and subependymal giant cell astrocytoma (SEGA) } \\
\text { - } \quad \text { Evaluate for TSC-associated neuropsychiatric disorder (TAND) } \\
\text { - During infancy, educate parents to recognize infantile spasms, even if none have occurred at time of first } \\
\text { diagnosis } \\
\text { - Obtain baseline routine electroencephalogram (EEG). If abnormal, especially if features of TAND are also } \\
\text { present, follow up with a 24-hour video EEG to assess for subclinical seizure activity }\end{array}$ \\
\hline Kidney & $\begin{array}{ll} & \text { Obtain MRI of the abdomen to assess for the presence of angiomyolipoma and renal cysts } \\
\text { - } & \text { Screen for hypertension by obtaining an accurate blood pressure } \\
\text { Evaluate renal function by determination of glomerular filtration rate }\end{array}$ \\
\hline Lung & $\begin{array}{l}\text { - Perform baseline pulmonary function testing (PFT and 6-minute walk test) and high-resolution chest } \\
\text { computed tomography (HRCT), even if asymptomatic, in patients at risk of developing } \\
\text { lymphangioleiomyomatosis (LAM), typically female patients } 18 \text { years or older. Adult male patients, if } \\
\text { symptomatic, should also undergo testing } \\
\text { - Provide counsel on smoking risks and estrogen use in adolescent and adult female patients }\end{array}$ \\
\hline Skin & - $\quad$ Perform a detailed clinical dermatologic inspection/examination \\
\hline Teeth & - $\quad$ Perform a detailed clinical dental inspection/examination \\
\hline Heart & $\begin{array}{l}\text { - } \quad \text { Consider fetal echocardiography to detect individuals with high risk of heart failure after delivery when } \\
\text { rhabdomyomas are identified via prenatal ultrasound } \\
\text { - } \quad \text { Obtain an echocardiogram in pediatric patients, especially if }<3 \text { years old } \\
\text { - Obtain an ECG in all ages to assess for underlying conduction defects }\end{array}$ \\
\hline Eye & $\begin{array}{l}\text { - Perform a complete ophthalmologic evaluation, including dilated fundoscopy, to assess for retinal lesions } \\
\text { and visual field deficits }\end{array}$ \\
\hline
\end{tabular}




\section{References}

[1] Hung CC, SuYN, ChienSC, LiouHH, ChenCC,ChenPC,et al. Molecular and clinical analyses of 84 patients with tuberous sclerosis complex. BMC Med Genet.2006; 7:72.

[2] Inoki K, Guan KL. Tuberous sclerosis complex, implication from a rare genetic disease to common cancer treatment. Hum Mol Genet. 2009;18:R94-100.

[3] Cutando A, Gil JA, López J. Oral health management implications in patients with tuberous sclerosis. Oral Surg Oral Med Oral Pathol Oral RadiolEndod. 2000;90:430-5.

[4] Hung CC,SuYN, ChienSC, LiouHH, ChenCC, ChenPC, et al. Molecular and clinical analyses of 84 patients with tuberous sclerosis complex. BMC Med Genet.2006; $7: 72$.

[5] Cutando A, Gil JA, López J. Oral health management implications in patients with tuberous sclerosis. Oral Surg Oral Med Oral Pathol Oral RadiolEndod. 2000;90:430-5.

[6] Schwartz RA, Fernández G, Kotulska K, Jozwiak S. Tuberous sclerosis

[7] complex: advances in diagnosis,genetics, and management. J Am AcadDermatol. 2007; 57:189-202.

[8] Korol UB, Schoor R, Nanda V, Almas K, Phelan JA. Gingival enlargement as a manifestation of tuberous sclerosis: case report and periodontal management. J Periodontol.2008; 79:759-63.

[9] TS Cheng. Tuberous sclerosis complex: an update Review Article Hong Kong J. Dermatol. Venereol. (2012) 20, 61-67.

[10] Fahsold R, Rott HD, Lorenz P. A third gene locus for tuberous sclerosis is closely linked to the phenylalaninehydroxylase gene locus. Hum Genet.1991; 88:85-90.

[11] Seibert D, Hong CH, Takeuchi F,Olsen C, Hathaway O, Moss J, et al.Recognition of tuberous sclerosis inadult women: delayed presentation with life-threatening consequences.Ann Intern Med 2011;154:806-13.

[12] Curatolo P. Seizures. In: CuratoloP,eds. Tuberous sclerosis complex: from basic science to clinical phenotypes.London: McKeith Press, 2003: 46-76.

[13] Schwartz RA, Fernández G, KotulskaK, Jóźwiak S. Tuberous sclerosis complex: advances indiagnosis,genetics, and management. JAmAcad Dermatol. 2007;57:189-202.

[14] Gupta S, Bhowate R, Degwekar SS.Clinical and radiological findings related to tuberous sclerosis complex: acase report. J Contemp Dent Pract.2008;9:85-91.

[15] Jozwiak S, Schwartz RA, JannigerCK, Michalowicz R, Chmielik J. Skin lesions in children with tuberoussclerosis complex: their prevalence,natural course, and diagnostic significance. Int $\mathrm{J}$ Dermatol 1998;37

[16] Lopez E, Escovich L, VignaA.Tuberous sclerosis: presentation of aclinical case with oral manifestations.Med Oral. 2003;8:122-8.

[17] Curatolo P. Seizures. In: CuratoloP,eds. Tuberous sclerosis complex: frombasic science to clinical phenotypes.London:McKeith Press, 2003: 46-76.
[18]Gupta S, Bhowate R, DegwekarSS.Clinical and radiological findingsrelated to tuberous sclerosis complex: acase report. J Contemp Dent Pract.2008;9:85-91. 